Article

\title{
Application of the Triazolization Reaction to Afford Dihydroartemisinin Derivatives with Anti-HIV Activity
}

\author{
Sampad Jana ${ }^{1,+}$, Shabina Iram ${ }^{2,+}$, Joice Thomas ${ }^{1}$, Muhammad Qasim Hayat ${ }^{2}$, \\ Christophe Pannecouque ${ }^{3, *}$ and Wim Dehaen ${ }^{1, *}$ \\ 1 Molecular Design and Synthesis, Department of Chemistry, KU Leuven, Celestijnenlaan 200F, 3001 Leuven, \\ Belgium; sampad.jana@kuleuven.be (S.J.); joicetk2003@gmail.com (J.T.) \\ 2 Department of Plant Biotechnology, Atta-Ur-Rahman School of Applied Biosciences (ASAB), \\ National University of Sciences and Technology (NUST), H-12 Islamabad, Pakistan; \\ shabinairam@hotmail.com (S.I.); mqasimhayat@hotmail.com (M.Q.H.) \\ 3 Department of Microbiology and Immunology, Laboratory of Virology and Chemotherapy, \\ Rega Institute for Medical Research, KU Leuven, Herestraat 49, B-3000 Leuven, Belgium \\ * Correspondence: christophe.pannecouque@kuleuven.be (C.P.); wim.dehaen@kuleuven.be (W.D.); \\ Tel.: +32-16-327-439 (W.D.); Fax: +32-16-327-990 (W.D.) \\ + These authors contributed equally.
}

Academic Editor: Svetlana B. Tsogoeva

Received: 4 January 2017; Accepted: 11 February 2017; Published: 17 February 2017

\begin{abstract}
Artemisinin and synthetic derivatives of dihydroartemisinin are known to possess various biological activities. Post-functionalization of dihydroartemisinin with triazole heterocycles has been proven to lead to enhanced therapeutic potential. By using our newly developed triazolization strategy, a library of unexplored fused and 1,5-disubstituted 1,2,3-triazole derivatives of dihydroartemisinin were synthesized in a single step. All these newly synthesized compounds were characterized and evaluated for their anti-HIV (Human Immunodeficiency Virus) potential in MT-4 cells. Interestingly; three of the synthesized triazole derivatives of dihydroartemisinin showed activities with half maximal inhibitory concentration $\left(\mathrm{IC}_{50}\right)$ values ranging from 1.34 to $2.65 \mu \mathrm{M}$.
\end{abstract}

Keywords: triazole; artemisinin; triazolization; organocatalytic; multicomponent reaction

\section{Introduction}

The human immunodeficiency virus (HIV), the causative agent of the acquired immunodeficiency syndrome (AIDS), has been plaguing the human race for more than thirty years [1]. According to the global statistics of UNAIDS, it has been estimated that globally 36.7 million people were suffering from HIV/AIDS in 2015 [2]. Even though more than thirty drugs targeting different steps of the viral life cycle are either approved or in clinical stages to treat HIV/AIDS [2], a cure remains elusive. Moreover, emergence of HIV strains that are no longer sensitive to the drug cocktails employed is leading to inability to completely block the viral replication [3]. Thus, finding new anti-HIV agents that are less toxic and more effective in targeting HIV reservoirs in the body is still needed. Artemisinin, a naturally occurring 1,2,4-trioxane sesquiterpene, first isolated in 1972 from a Chinese medicinal plant (Artemisia annua L.) that had been used as a treatment for fever for many centuries [4]. Interestingly, artemisinin has been used successfully at nanomolar concentrations against both chloroquine-sensitive and -resistant strains of Plasmodium falciparum. However, its therapeutic efficiency is not optimal due to poor oral bioavailability and limited solubility $[5,6]$. Reduction of the carbonyl group of artemisinin leads to the synthesis of dihydroartemisinin in high yields without disrupting the unusual peroxide linkage of artemisinin which has in turn lead to the development of a series of semi-synthetic first generation derivatives including the oil soluble artemether and arteether, and water soluble sodium 
artesunate (Figure 1) [5]. Derivatives of artemisinin have shown improved potency as antimalarial and anticancer agent as compared to artemisinin itself [5,7].<smiles>CC1CCC2C(C)CC[C@@H](C)[C@]23OC(=O)C(C)[C@H]3O1</smiles>

Artemisinin

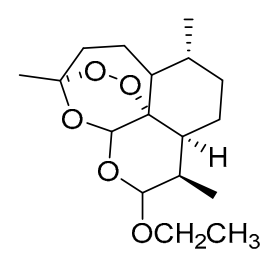

Arteether

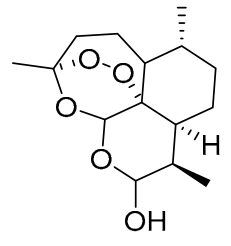

Dihydroartemisinin

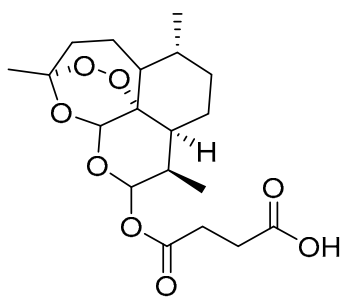

Artesunic acid

Figure 1. Structures of artemisinin and its semi-synthetic derivatives.

Dihydroartemisinin has become a subject of considerable interest in medicinal chemistry for its therapeutic value, better solubility, and being a versatile precursor for the synthesis of wide variety of other artemisinin derivatives [4]. Furthermore, derivatives of dihydroartemisinin are found to have antiproliferative, antibacterial, antiviral, and immunosuppressive activities [8-21]. Even though it displays a high activity profile, dihydroartemisinin does suffer some drawbacks such as neurotoxicity in animal models, short pharmacological half-life, and recrudescence of the disease [22,23]. The shortcomings of the current artemisinin derivatives and emergence of multidrug resistance for artemisinin based combination therapies [24] are the motivation to search for novel artemisinin compounds.

Although 1,2,3-triazole derivatives of artemisinin have been synthesized and evaluated for biological activity [25,26], no attempt has been made to synthesize 1,5-disubstituted 1,2,3-triazole derivatives of dihydroartemisinin in a single step and metal-free conditions. The widespread applications of 1,2,3-triazoles have triggered the demand for metal free and easier access to this privileged scaffold. Herein we disclose the implementation of our recently developed triazolization strategy [27-29] in which dihydroartemisinin scaffold was joined with variety of interesting heterocyclic moieties. We presume that this strategy could help in synthesizing a series of compound with minimal effort to obtain various fused and 1,5-disubstituted triazole derivatives of dihydroartemisinin.

\section{Results and Discussion}

\subsection{Organocatalytic Synthesis of Triazole Functionalized Artemisinin}

As an effective method of functionalizing dihydroartemisinin with triazole heterocycle, we implemented our recently developed triazolization strategy [27-29]. The method generally involves the reaction of a primary amine and an enolizable ketone 6 in the presence of 4-nitrophenyl azide 7 as a source of dinitrogen. The mechanistic study of this reaction indicated that an equilibrium exists between imine and enamine followed by an enamine mediated [3+2] cycloaddition reaction. This leads to the formation of a triazole intermediate followed by elimination of nitroaniline which gave the fused or 1,5-disubstituted 1,2,3-triazole derivative of dihydroartemisinin. 
Initially, the amine functionalized dihydroartemisinin $\mathbf{5}$ was synthesized by a previously reported procedure [30]. It involves the conversion of dihydroartemisinin into 10-bromoethoxydihydroartemisinin (2) by using 2-bromoethanol (3) in the presence $\mathrm{of}^{\mathrm{BF}} \mathrm{BF}_{3} \cdot \mathrm{Et}_{2} \mathrm{O}$ as a catalyst. Reaction of sodium azide with 10-bromoethoxydihydroartemisinin (2) afforded 2 -(10ß-dihydroartemisinoxy) ethyl azide (4) in 95\% isolated yield (Scheme 1). The azido compound was then reduced to 2-(10ß-dihydroartemisinoxy) ethyl amine (5) in $74 \%$ yield via a Staudinger reduction (Scheme 1).

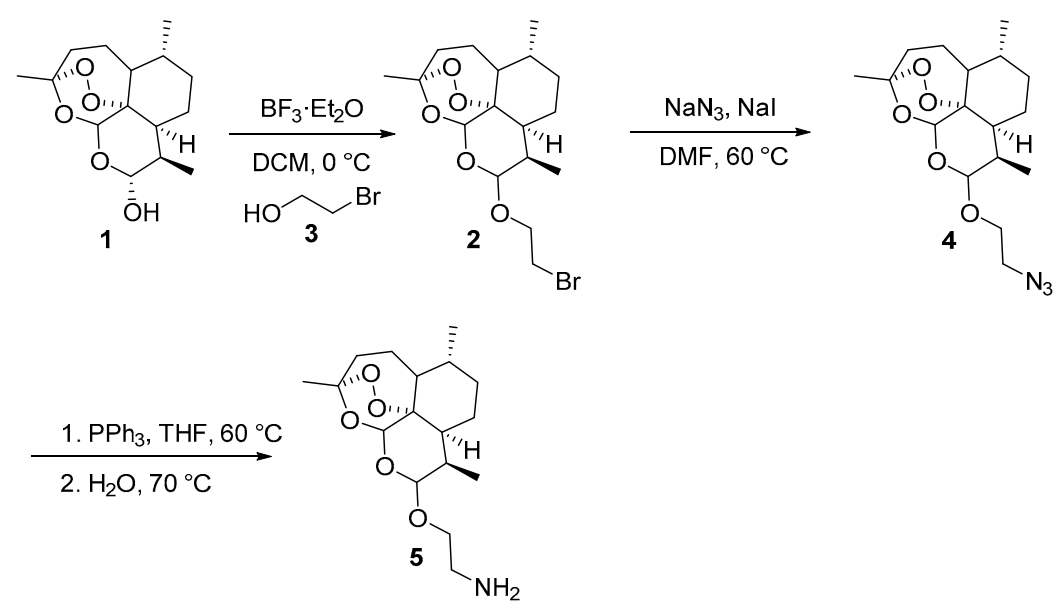

Scheme 1. Synthetic route towards the preparation of amine precursor 4. DCM: dichloromethane; DMF: dimethylformamide; THF: tetrahydrofuran.

The amine-modified dihydroartemisinin was then tested for the triazolization strategy with various aromatic and enolizable ketones. Cyclic ketones such as tetralones and their derivatives reacted smoothly under the modified triazolization conditions leading to the expected product in moderate yield. Acetophenone was also converted to the desired product $8 \mathbf{f}$ (Table 1). Next, the versatility of this triazolization reaction was shown by functionalizing the modified dihydroartemisinin $\mathbf{5}$ with the male sex hormone analogue dihydrotestosterone and the triterpene betulonic acid giving rise to the fused triazole derivatives $\mathbf{8 k}$ and $\mathbf{8 1}$, respectively, in moderate yield shown in Table 1.

In the next series of experiments, we reversed the strategy by functionalizing dihydroartemisinin scaffold with symmetrical enolizable cyclic ketone. The building block 9 was obtained by classical DCC $\left(N, N^{\prime}\right.$-dicyclohexylcarbodiimide) coupling reaction of dihydroartemisinin with cyclohexanone-4-carboxylic acid isolated in $82 \%$ yield (Scheme 2).

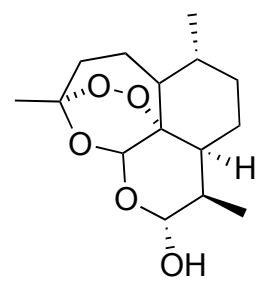

1

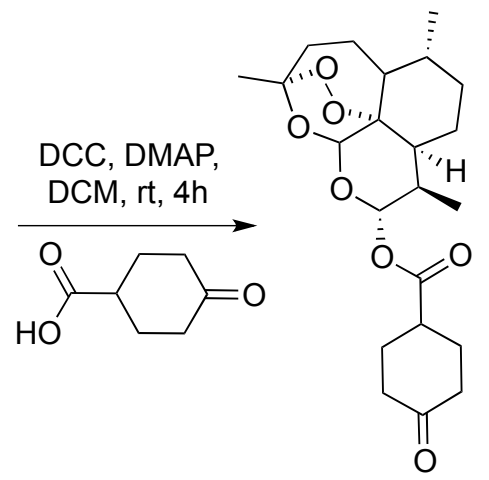

9

Scheme 2. Synthetic route towards the preparation of keto precursor 9. DCC: $N, N^{\prime}$-dicyclohexylcarbodiimide; DMAP: 4-dimethylaminopyridine 
Table 1. Substrate scope with respect to ketones ${ }^{\text {a }}$.
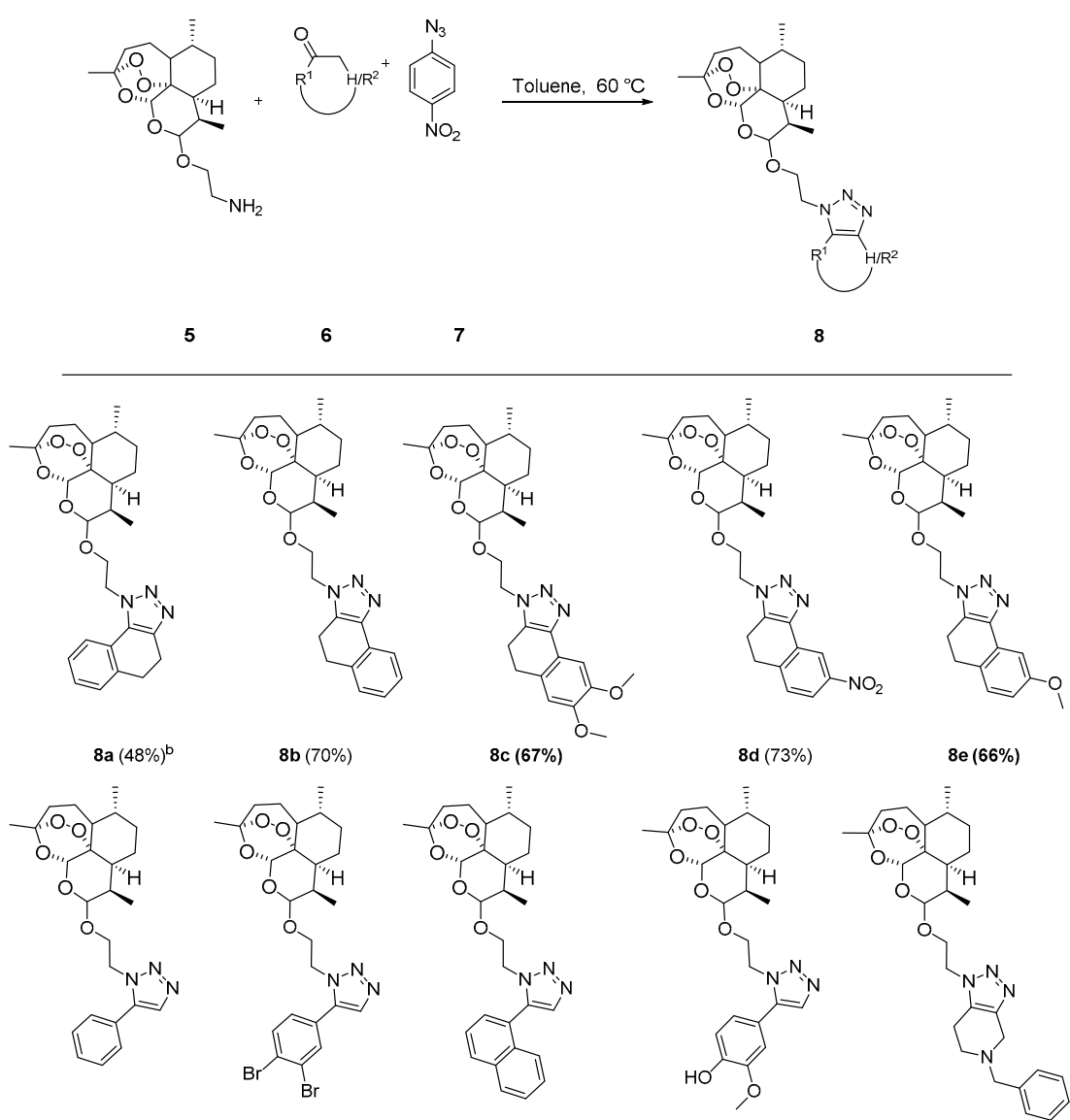

$8 f(49 \%)^{\mathrm{b}}$

$\mathbf{8 g}(37 \%)^{\mathrm{b}}$

$8 \mathrm{~h}(53 \%)^{\mathrm{b}}$

$8 \mathbf{i}(38 \%)^{b}$

8j $(63 \%)$
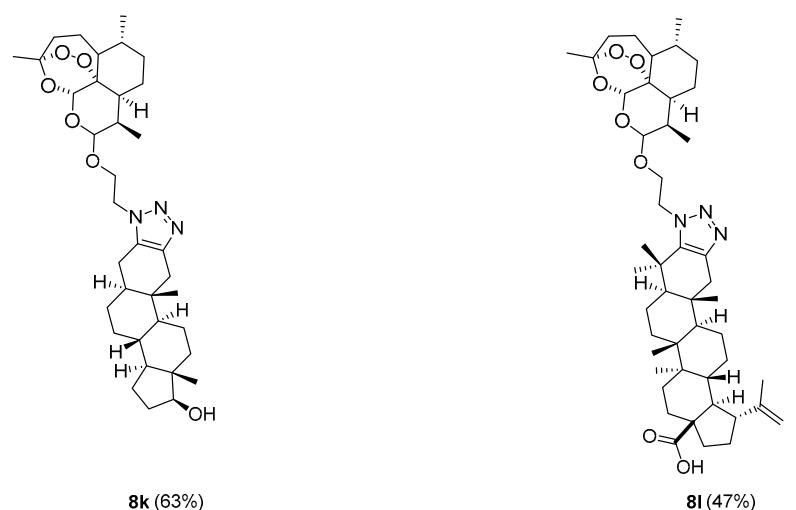

$8 \mathbf{k}(63 \%)$

$81(47 \%)$

a Reagents and conditions: 5 (1.0 equiv.), 6 (1.0 equiv.), 7 (1.2 equiv.), toluene $(0.4 \mathrm{~mL}), 60{ }^{\circ} \mathrm{C}, 16 \mathrm{~h}$, isolated yield; ${ }^{\mathrm{b}} 24 \mathrm{~h}$.

The versatility of our triazolization methodology was further exploited by condensing with various commercial and biologically relevant primary amine derivatives. Ketone-modified dihydroartemisinin 9 was treated with various benzylamines which led to the synthesis of triazole conjugate in good yield (Table 2). Tryptamine also works fine under these reaction circumstances leading to the expected product 11d in moderate yield (Table 2). 
Table 2. Substrate scope with respect to amines ${ }^{\text {a }}$.

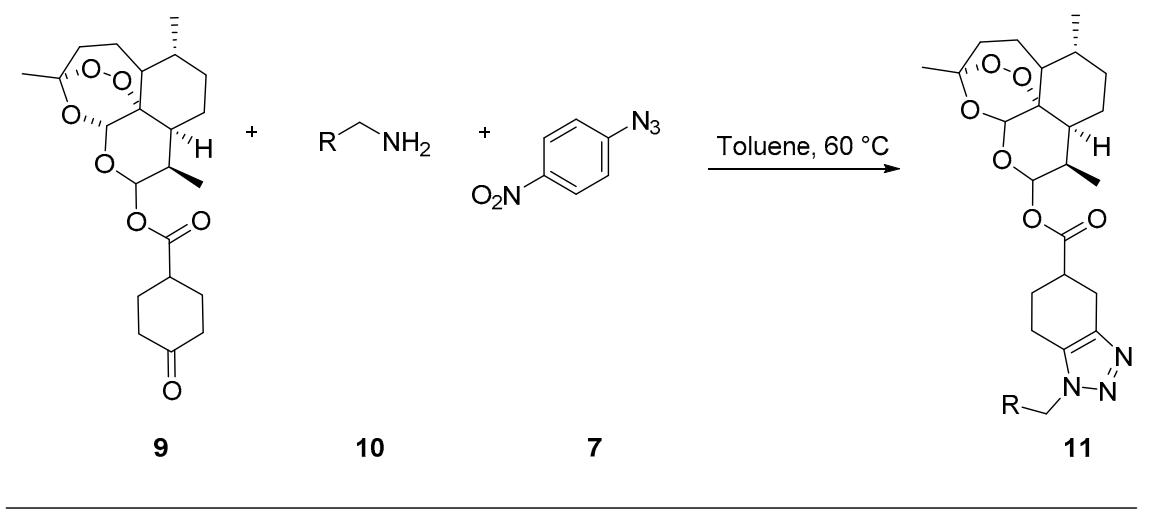

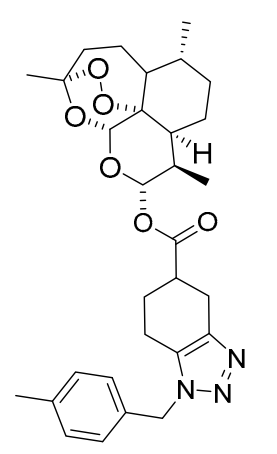

$11 \mathrm{a}(67 \%)$

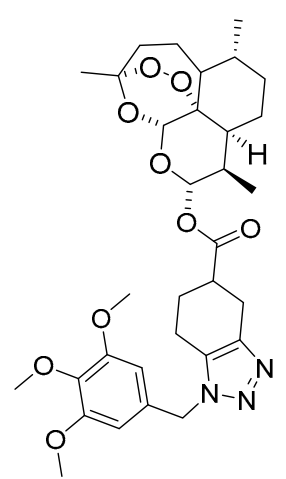

$11 b(63 \%)$

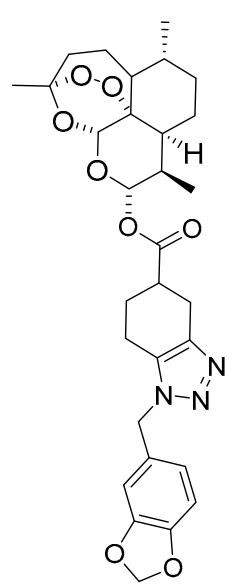

11c $(61 \%)$

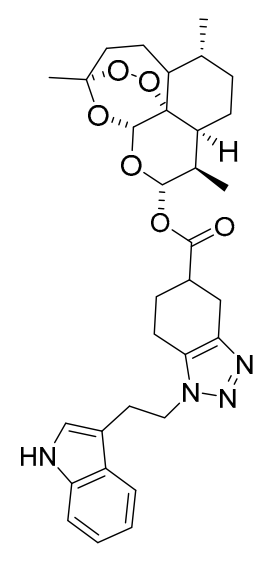

$11 d(46 \%)$

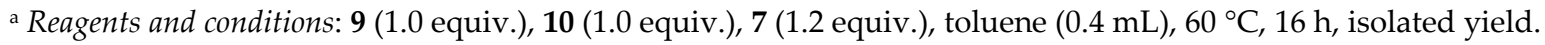

\subsection{Anti-Human Immunodeficiency Virus Activity Evaluation}

The newly synthesized dihydroartemisinin triazole derivatives were evaluated for their inhibitory effects $\left(\mathrm{IC}_{50}\right)$ on the replication of wild-type HIV-1 (III $)$ and HIV-2 (ROD) in MT-4 cell cultures, in parallel with their cytotoxicities $\left(\mathrm{CC}_{50}\right)$ using the 3-(4,5-dimethylthiazol-2-yl)-2,5-diphenyl tetrazolium bromide (MTT) method [31]. A series of nucleoside reverse transcriptase inhibitors (NRTIs) - -i.e., azidothymidine (AZT), lamivudine (3TC) and didanosine (DDI)—and non-nucleoside reverse transcriptase inhibitors (NNRTIs) -i.e., nevirapine (NVP), efavirenz (EFV), and etravirine (ETR)—were included as reference compounds. The biological results are represented as $\mathrm{IC}_{50}$ and $\mathrm{CC}_{50}$ values in Table 3.

Most of the new triazole analogues of dihydroartemisinin are completely devoid of anti-HIV activity. However, the unsubstituted $\beta$-2-tetralone analogue $\mathbf{8 b}$ exhibited moderate activity against wild-type (wt) HIV-1 III $_{B}$ with IC $_{50}$ value of $2.78 \mu \mathrm{M}$, whereas its $\alpha$-tetralone analogue $8 \mathrm{a}$ did not show any activity. Both the mono and di-methoxy $\beta$-tetralone analogues $\mathbf{8 e}$ and $\mathbf{8 c}$, are slightly less active against HIV-1 wt IC 50 values of 5.18 and $4.06 \mu \mathrm{M}$ respectively. The active molecules were also evaluated for their inhibitory activity against a double reverse transcriptase mutant (K103N; Y181C) HIV-1 strain (RES056). The derivatives $\mathbf{8 b}, \mathbf{8} \mathbf{c}$ and $\mathbf{8 e}$, just like the first generation NNRTI nevirapine, completely lose their inhibitory activity, whereas the anti-HIV activity of efavirenz and etravirine is only slightly affected. Therefore, the active $\beta$-tetralone derivatives most probably act via an NNRTI-type mode of action. 
Table 3. In vitro anti-HIV activity and cytotoxicity of triazole derivatives of dihydroartemisinin.

\begin{tabular}{|c|c|c|c|c|}
\hline Compound & \multicolumn{3}{|c|}{$\mathrm{IC}_{50}(\mu \mathrm{M})^{\mathrm{a}}$} & $\mathrm{CC}_{50}(\mu \mathrm{M})^{\mathrm{b}}$ \\
\hline $8 a$ & $>10.3$ & $>10.3$ & $\mathrm{NT}^{\mathrm{c}}$ & $>10.3$ \\
\hline $8 c$ & 4.06 & $>21.2$ & $>21.2$ & 21.2 \\
\hline $8 e$ & 5.18 & $>14.9$ & $>14.9$ & 14.9 \\
\hline Didanosine & 76.0 & 82.1 & NT & $>212$ \\
\hline Nevirapine & 0.075 & $>15.0$ & $>15.0$ & $>15.0$ \\
\hline Efavirenz & 0.0024 & $>6.3$ & 0.18 & $>6.3$ \\
\hline Etravirine & 0.0034 & $>2.29$ & 0.045 & 2.29 \\
\hline
\end{tabular}

${ }^{\mathrm{a}} \mathrm{IC}_{50}$ : concentration of compound required to achieve $50 \%$ protection of MT- 4 cell cultures against HIV-1-induced cytotoxicity, as determined by the MTT (3-(4,5-dimethylthiazol-2-yl)-2,5-diphenyltetrazolium bromide) method; ${ }^{\mathrm{b}} \mathrm{CC}_{50}$ : concentration required to reduce the viability of mock-infected cell cultures by $50 \%$, as determined by the MTT method; ${ }^{c}$ Not tested.

\section{Experimental Section}

\subsection{General Information}

${ }^{1} \mathrm{H}$ - and ${ }^{13} \mathrm{C}-\mathrm{NMR}$ spectra were recorded on commercial instruments (Bruker AMX $400 \mathrm{MHz}$ or Bruker Avance $\mathrm{II}^{+} 600 \mathrm{MHz}$, Bruker, Rheinstetten, Germany) and chemical shifts $(\delta)$ are referenced to tetramethylsilane $\left({ }^{1} \mathrm{H}\right)$, or the internal (NMR) solvent signal $\left({ }^{13} \mathrm{C}\right)$. For column chromatography 70-230 mesh silica 60 (E. M. Merck, Steinheim am Albuch, Germany) was used as the stationary phase. Chemicals received from commercial sources were used without further purification. Synthesis of 5 was carried out based on the literature report and exactly matched with reported NMR data [30]. Other products' NMR spectra see Supplementary Materials.

\subsection{General Procedure for Modified Triazolization Reaction}

A flame-dried screw-capped reaction tube equipped with magnetic stirring bar was charged with amine, ketone, 4-nitrophenylazide, and $4 \AA$ molecular sieves. The mixture was dissolved in toluene $(0.4 \mathrm{~mL})$ and stirred at $60^{\circ} \mathrm{C}$ for $18-36 \mathrm{~h}$. The reaction was monitored by Thin-layer chromatography and after completion of reaction, the solvent was removed in vacuo. The crude reaction mixture was then subsequently purified by column chromatography (silica gel) first using DCM (dichloromethane) as eluent to remove all 4-nitroaniline formed during the reaction, followed by a mixture of heptane and ethyl acetate as the eluent to afford the title product.

\subsection{Characterization of the Products}

1-(2-(((3R,6R,8aS,9R,10R,12R,12aR)-3,6,9-Trimethyldecahydro-12H-3,12-epoxy[1,2]dioxepino[4,3-i]isochromen-10yl)oxy)ethyl)-4,5-dihydro-1H-naphtho[1,2-d][1,2,3]triazole (8a): 5 (60 mg, $0.183 \mathrm{mmol}), \alpha$-tetralone $(26.8 \mathrm{mg}, 0.183 \mathrm{mmol})$, 4-nitrophenyl azide $(36.1 \mathrm{mg}, 0.220 \mathrm{mmol})$. Reaction time was $24 \mathrm{~h}$. The product was purified by flash column chromatography (first DCM, followed by EtOAc/heptane $=3: 2)$ to afford $8 \mathbf{a}(42 \mathrm{mg}, 48 \%)$ as an off-white semisolid: ${ }^{1} \mathrm{H}-\mathrm{NMR}\left(400 \mathrm{MHz}, \mathrm{CDCl}_{3}\right)$ $\delta 7.94(\mathrm{~d}, J=7.4 \mathrm{~Hz}, 1 \mathrm{H}), 7.30(\mathrm{td}, J=7.4,1.8 \mathrm{~Hz}, 1 \mathrm{H}), 7.24-7.17(\mathrm{~m}, 2 \mathrm{H}), 5.38(\mathrm{~s}, 1 \mathrm{H}), 4.62(\mathrm{~d}, J=8.0 \mathrm{~Hz}$, $1 \mathrm{H}), 4.60-4.54(\mathrm{~m}, 1 \mathrm{H}), 4.53-4.44(\mathrm{~m}, 1 \mathrm{H}), 4.23(\mathrm{dt}, J=10.6,4.3 \mathrm{~Hz}, 1 \mathrm{H}), 3.91(\mathrm{ddd}, J=10.7,8.6,4.0 \mathrm{~Hz}$, $1 \mathrm{H}), 3.09-2.91(\mathrm{~m}, 4 \mathrm{H}), 1.87-1.81(\mathrm{~m}, 1 \mathrm{H}), 1.71-1.62(\mathrm{~m}, 3 \mathrm{H}), 1.60-1.49(\mathrm{~m}, 3 \mathrm{H}), 1.47(\mathrm{~s}, 3 \mathrm{H}), 1.44-1.35$ $(\mathrm{m}, 1 \mathrm{H}), 1.29(\mathrm{dt}, J=14.4,3.2 \mathrm{~Hz}, 1 \mathrm{H}), 1.22-1.09(\mathrm{~m}, 2 \mathrm{H}), 1.06-0.95(\mathrm{~m}, 1 \mathrm{H}), 0.88(\mathrm{dd}, J=6.3,3.6 \mathrm{~Hz}$, 6H). ${ }^{13} \mathrm{C}-\mathrm{NMR}\left(101 \mathrm{MHz}, \mathrm{CDCl}_{3}\right) \delta 143.34,134.03,133.69,129.04,128.19,127.37,127.35,122.16,107.27$, 101.43, 97.25, 82.73, 68.54, 48.50, 45.24, 44.11, 39.98, 35.27, 34.55, 34.52, 32.81, 28.81, 23.87, 22.17, 19.41, $19.34,18.76$. 
3-(2-(((3R,6R,8aS,9R,10R,12R,12aR)-3,6,9-Trimethyldecahydro-12H-3,12-epoxy[1,2]dioxepino[4,3-i]isochromen-10yl)oxy)ethyl)-4,5-dihydro-3H-naphtho[1,2-d][1,2,3]triazole (8b): 5 (60 mg, $0.183 \mathrm{mmol}), \beta$-tetralone ( $26.8 \mathrm{mg}, 0.183 \mathrm{mmol})$, 4-nitrophenyl azide ( $36.1 \mathrm{mg}, 0.220 \mathrm{mmol})$. Reaction time was $16 \mathrm{~h}$. The product was purified by flash column chromatography (first DCM, then EtOAc/heptane $=3: 2$ ) to afford $\mathbf{8 b}$

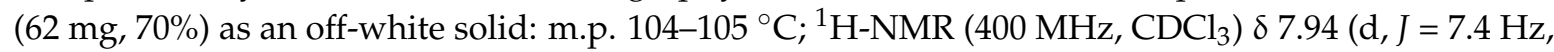
$1 \mathrm{H}), 7.30(\mathrm{td}, J=7.4,1.8 \mathrm{~Hz}, 1 \mathrm{H}), 7.24-7.17(\mathrm{~m}, 2 \mathrm{H}), 5.38(\mathrm{~s}, 1 \mathrm{H}), 4.62(\mathrm{~d}, J=8.0 \mathrm{~Hz}, 1 \mathrm{H}), 4.60-4.54$ $(\mathrm{m}, 1 \mathrm{H}), 4.53-4.44(\mathrm{~m}, 1 \mathrm{H}), 4.23(\mathrm{dt}, J=10.6,4.3 \mathrm{~Hz}, 1 \mathrm{H}), 3.91(\mathrm{ddd}, J=10.7,8.6,4.0 \mathrm{~Hz}, 1 \mathrm{H}), 3.09-2.91$ $(\mathrm{m}, 4 \mathrm{H}), 1.87-1.81(\mathrm{~m}, 1 \mathrm{H}), 1.71-1.62(\mathrm{~m}, 3 \mathrm{H}), 1.60-1.49(\mathrm{~m}, 3 \mathrm{H}), 1.47(\mathrm{~s}, 3 \mathrm{H}), 1.44-1.35(\mathrm{~m}, 1 \mathrm{H}), 1.29$ $(\mathrm{dt}, J=14.4,3.2 \mathrm{~Hz}, 1 \mathrm{H}), 1.22-1.09(\mathrm{~m}, 2 \mathrm{H}), 1.06-0.95(\mathrm{~m}, 1 \mathrm{H}), 0.88(\mathrm{dd}, J=6.3,3.6 \mathrm{~Hz}, 6 \mathrm{H}) .{ }^{13} \mathrm{C}-\mathrm{NMR}$ $\left(101 \mathrm{MHz}, \mathrm{CDCl}_{3}\right) \delta 143.34,134.03,133.69,129.04,128.19,127.37,127.35,122.16,107.27,101.43,97.25$, $82.73,68.54,48.50,45.24,44.11,39.98,35.27,34.55,34.52,32.81,28.81,23.87,22.17,19.41,19.34,18.76$.

7,8-Dimethoxy-3-(2-(((3R,6R,8aS,9R,10R,12R,12aR)-3,6,9-trimethyldecahydro-12H-3,12-epoxy[1,2]dioxepino[4,3-i] isochromen-10-yl)oxy)ethyl)-4,5-dihydro-3H-naphtho[1,2-d][1,2,3]triazole (8c): 5 (60 mg, $0.183 \mathrm{mmol}$ ), 6,7-dimethoxy-3,4-dihydronaphthalen-2(1H)-one ( $37.8 \mathrm{mg}, 0.183 \mathrm{mmol})$, 4-nitrophenyl azide ( $36.1 \mathrm{mg}$, $0.220 \mathrm{mmol}$ ). Reaction time was $16 \mathrm{~h}$. The product was purified by flash column chromatography (first DCM, followed by EtOAc/heptane $=3: 2)$ to give $8 \mathrm{c}(67 \mathrm{mg}, 67 \%)$ as an off-white semisolid: ${ }^{1} \mathrm{H}-\mathrm{NMR}\left(400 \mathrm{MHz}, \mathrm{CDCl}_{3}\right) \delta 7.49(\mathrm{~s}, 1 \mathrm{H}), 6.76(\mathrm{~s}, 1 \mathrm{H}), 5.38(\mathrm{~s}, 1 \mathrm{H}), 4.62(\mathrm{~d}, J=7.9 \mathrm{~Hz}, 1 \mathrm{H}), 4.59-4.53$ $(\mathrm{m}, 1 \mathrm{H}), 4.51-4.44(\mathrm{~m}, 1 \mathrm{H}), 4.26-4.18(\mathrm{~m}, 1 \mathrm{H}), 3.95(\mathrm{~s}, 3 \mathrm{H}), 3.89(\mathrm{~s}, 4 \mathrm{H}), 3.05-2.84(\mathrm{~m}, 4 \mathrm{H}), 1.88-1.79$ $(\mathrm{m}, 1 \mathrm{H}), 1.71-1.62(\mathrm{~m}, 3 \mathrm{H}), 1.60-1.50(\mathrm{~m}, 3 \mathrm{H}), 1.47(\mathrm{~s}, 3 \mathrm{H}), 1.44-1.35(\mathrm{~m}, 1 \mathrm{H}), 1.33-1.23(\mathrm{~m}, 2 \mathrm{H})$, 1.21-1.10 (m, 1H), 1.08-0.95 (m, 1H), 0.91-0.85 (m, 6H). ${ }^{13} \mathrm{C}-\mathrm{NMR}\left(101 \mathrm{MHz}, \mathrm{CDCl}_{3}\right) \delta 148.40,148.20$, $143.46,133.09,125.92,121.85,111.89,107.25,105.67,101.41,97.24,82.71,68.50,56.26,56.18,48.52,45.23$, $44.12,39.97,35.26,34.55,34.51,32.80,28.45,23.85,22.16,19.62,19.32,18.74$.

8-Nitro-3-(2-(( $(3 R, 6 R, 8 a S, 9 R, 10 R, 12 R, 12 a R)-3,6,9-t r i m e t h y l d e c a h y d r o-12 H-3,12-e p o x y[1,2]$ dioxepino[4,3-i]isochromen10-yl)oxy)ethyl)-4,5-dihydro-3H-naphtho[1,2-d][1,2,3]triazole (8d): 5 (60 mg, $0.183 \mathrm{mmol}), 7$-nitro-3, 4-dihydronaphthalen-2(1H)-one ( $35 \mathrm{mg}, 0.183 \mathrm{mmol})$, 4-nitrophenyl azide (36.1 mg, $0.220 \mathrm{mmol}$ ). Reaction time was $16 \mathrm{~h}$. Flash column chromatography (first DCM, followed by EtOAc/heptane = 3:2) afforded $8 \mathrm{~d}(70.4 \mathrm{mg}, 73 \%)$ as an off-white semisolid: ${ }^{1} \mathrm{H}-\mathrm{NMR}\left(400 \mathrm{MHz}, \mathrm{CDCl}_{3}\right) \delta 8.78(\mathrm{~d}, J=2.2 \mathrm{~Hz}$, $1 \mathrm{H}), 8.12(\mathrm{dd}, J=8.3,2.3 \mathrm{~Hz}, 1 \mathrm{H}), 7.48(\mathrm{~d}, J=8.4 \mathrm{~Hz}, 1 \mathrm{H}), 5.38(\mathrm{~s}, 1 \mathrm{H}), 4.91-4.87(\mathrm{~m}, 2 \mathrm{H}), 4.61$ $(\mathrm{d}, J=7.9 \mathrm{~Hz}, 1 \mathrm{H}), 4.45-4.39(\mathrm{~m}, 1 \mathrm{H}), 4.15-4.01(\mathrm{~m}, 1 \mathrm{H}), 3.15-3.02(\mathrm{~m}, 4 \mathrm{H}), 1.86-1.79(\mathrm{~m}, 1 \mathrm{H}), 1.69-1.61$ $(\mathrm{m}, 3 \mathrm{H}), 1.55-1.48(\mathrm{~m}, 3 \mathrm{H}), 1.44(\mathrm{~s}, 3 \mathrm{H}), 1.36-1.32(\mathrm{~m}, 1 \mathrm{H}), 1.32-1.27(\mathrm{~m}, 2 \mathrm{H}), 1.21-1.11(\mathrm{~m}, 1 \mathrm{H})$, $1.02-0.92(\mathrm{~m}, 1 \mathrm{H}), 0.88-0.76(\mathrm{~m}, 6 \mathrm{H}) .{ }^{13} \mathrm{C}-\mathrm{NMR}\left(101 \mathrm{MHz}, \mathrm{CDCl}_{3}\right) \delta 147.43,145.81,144.66,131.02$, $129.79,126.95,123.16,118.31,107.19,101.28,97.24,82.76,77.16,68.37,50.36,45.28,44.08,39.56,35.21$, $34.58,34.51,32.61,30.78,29.85,23.85,22.17,20.38,19.18,18.80$.

8-Methoxy-3-(2-(((3R,6R,8aS,9R,10R,12R,12aR)-3,6,9-trimethyldecahydro-12H-3,12-epoxy[1,2]dioxepino[4,3-i] isochromen-10-yl)oxy)ethyl)-4,5-dihydro-3H-naphtho[1,2-d][1,2,3]triazole (8e): 5 (60 mg, $0.183 \mathrm{mmol}$ ), 7-methoxy-3,4-dihydronaphthalen-2(1H)-one (32.3 mg, $0.183 \mathrm{mmol})$, 4-nitrophenyl azide (36.1 mg, $0.220 \mathrm{mmol}$ ). Reaction time was $16 \mathrm{~h}$. The product was purified by flash column chromatography (first DCM, followed by EtOAc/heptane $=3: 2)$ to afford $8 \mathbf{e}(62 \mathrm{mg}, 66 \%)$ as an off-white semisolid: ${ }^{1} \mathrm{H}-\mathrm{NMR}\left(400 \mathrm{MHz}, \mathrm{CDCl}_{3}\right) \delta 7.51(\mathrm{~d}, J=2.7 \mathrm{~Hz}, 1 \mathrm{H}), 7.13(\mathrm{~d}, J=8.3 \mathrm{~Hz}, 1 \mathrm{H}), 6.75(\mathrm{dd}, J=8.3$, $2.7 \mathrm{~Hz}, 1 \mathrm{H}), 5.37(\mathrm{~s}, 1 \mathrm{H}), 4.62(\mathrm{~d}, J=8.0 \mathrm{~Hz}, 1 \mathrm{H}), 4.60-4.54(\mathrm{~m}, 1 \mathrm{H}), 4.53-4.45(\mathrm{~m}, 1 \mathrm{H}), 4.27-4.19(\mathrm{~m}$, $1 \mathrm{H}), 3.95-3.88(\mathrm{~m}, 1 \mathrm{H}), 3.86(\mathrm{~s}, 3 \mathrm{H}), 3.04-2.88(\mathrm{~m}, 4 \mathrm{H}), 1.86-1.80(\mathrm{~m}, 1 \mathrm{H}), 1.71-1.62(\mathrm{~m}, 3 \mathrm{H}), 1.61-1.49$ $(\mathrm{m}, 3 \mathrm{H}), 1.47(\mathrm{~s}, 3 \mathrm{H}), 1.43-1.35(\mathrm{~m}, 1 \mathrm{H}), 1.34-1.27(\mathrm{~m}, 2 \mathrm{H}), 1.22-1.15(\mathrm{~m}, 1 \mathrm{H}), 1.06-0.95(\mathrm{~m}, 1 \mathrm{H})$, 0.90-0.86 (m, 6H). ${ }^{13} \mathrm{C}-\mathrm{NMR}\left(101 \mathrm{MHz}, \mathrm{CDCl}_{3}\right) \delta 159.10,143.39,134.39,129.97,129.15,125.68,113.95$, 107.26, 106.62, 101.41, 97.23, 82.71, 68.49, 55.62, 48.52, 45.22, 44.10, 39.95, 35.25, 34.54, 34.50, 32.79, 27.96, $23.85,22.15,19.63,19.32,18.74$.

5-Phenyl-1-(2-(((3R,6R,8aS,9R,10R,12R,12aR)-3,6,9-trimethyldecahydro-12H-3,12-epoxy[1,2]dioxepino[4,3-i] isochromen-10-yl)oxy)ethyl)-1H-1,2,3-triazole (8f): $5(60 \mathrm{mg}, 0.183 \mathrm{mmol})$, acetophenone $(22 \mathrm{mg}$, $0.183 \mathrm{mmol})$, 4-nitrophenyl azide ( $36.1 \mathrm{mg}, 0.220 \mathrm{mmol})$. Reaction time was $24 \mathrm{~h}$. The product was 
purified by flash column chromatography (at first DCM followed by EtOAc/heptane $=3: 2$ ) to give $8 \mathbf{f}$ (41 mg, 49\%) as an off-white semisolid: ${ }^{1} \mathrm{H}-\mathrm{NMR}\left(400 \mathrm{MHz}, \mathrm{CDCl}_{3}\right) \delta 7.69(\mathrm{~s}, 1 \mathrm{H}), 7.53-7.44(\mathrm{~m}, 5 \mathrm{H})$, $5.35(\mathrm{~s}, 1 \mathrm{H}), 4.64-4.46(\mathrm{~m}, 3 \mathrm{H}), 4.32-4.21(\mathrm{~m}, 1 \mathrm{H}), 4.12-4.00(\mathrm{~m}, 1 \mathrm{H}), 1.88-1.79(\mathrm{~m}, 1 \mathrm{H}), 1.70-1.62(\mathrm{~m}$, $3 \mathrm{H}), 1.61-1.49(\mathrm{~m}, 3 \mathrm{H}), 1.47(\mathrm{~s}, 3 \mathrm{H}), 1.42-1.33(\mathrm{~m}, 1 \mathrm{H}), 1.31-1.22(\mathrm{~m}, 2 \mathrm{H}), 1.21-1.12(\mathrm{~m}, 1 \mathrm{H}), 1.06-0.94$ $(\mathrm{m}, 1 \mathrm{H}), 0.89-0.81(\mathrm{~m}, 6 \mathrm{H}) .{ }^{13} \mathrm{C}-\mathrm{NMR}\left(101 \mathrm{MHz}, \mathrm{CDCl}_{3}\right) \delta 138.90,132.92,129.45,129.26,129.10,127.25$, 107.23, 101.60, 97.23, 82.71, 68.08, 48.04, 45.27, 44.12, 39.70, 35.27, 34.57, 34.53, 32.79, 23.86, 22.17, $19.19,18.76$.

5-(3,4-Dibromophenyl)-1-(2-(((3R,6R,8aS,9R,10R,12R,12aR)-3,6,9-trimethyldecahydro-12H-3,12-epoxy[1,2] dioxepino[4,3-i]isochromen-10-yl)oxy)ethyl)-1H-1,2,3-triazole $(8 \mathrm{~g}): \quad 5 \quad(60 \mathrm{mg}, \quad 0.183 \mathrm{mmol})$, 1-(3,4-dibromophenyl)ethan-1-one (51 $\mathrm{mg}, 0.183 \mathrm{mmol})$, 4-nitrophenyl azide (36.1 $\mathrm{mg}$, $0.220 \mathrm{mmol}$ ). Reaction time was $36 \mathrm{~h}$. Flash column chromatography purification (DCM first, followed by EtOAc/heptane = 3:2) afforded $8 \mathrm{~g}(42 \mathrm{mg}, 37 \%)$ as an off-white solid: m.p. $105-106{ }^{\circ} \mathrm{C}$; ${ }^{1} \mathrm{H}-\mathrm{NMR}\left(400 \mathrm{MHz}, \mathrm{CDCl}_{3}\right) \delta 7.83(\mathrm{~d}, J=2.0 \mathrm{~Hz}, 1 \mathrm{H}), 7.73-7.69(\mathrm{~m}, 2 \mathrm{H}), 7.32(\mathrm{dd}, J=8.3,2.1 \mathrm{~Hz}, 1 \mathrm{H})$, $5.31(\mathrm{~s}, 1 \mathrm{H}), 4.60-4.52(\mathrm{~m}, 3 \mathrm{H}), 4.28-4.22(\mathrm{~m}, 1 \mathrm{H}), 4.07-4.00(\mathrm{~m}, 1 \mathrm{H}), 1.86-1.80(\mathrm{~m}, 1 \mathrm{H}), 1.71-1.64(\mathrm{~m}$, $2 \mathrm{H}), 1.62-1.56(\mathrm{~m}, 3 \mathrm{H}), 1.54-1.49(\mathrm{~m}, 1 \mathrm{H}), 1.46(\mathrm{~s}, 3 \mathrm{H}), 1.32-1.22(\mathrm{~m}, 3 \mathrm{H}), 1.19-1.10(\mathrm{~m}, 2 \mathrm{H}), 1.04-0.95$ $(\mathrm{m}, 1 \mathrm{H}), 0.88(\mathrm{~d}, J=5.7 \mathrm{~Hz}, 3 \mathrm{H}), 0.84(\mathrm{~d}, J=7.1 \mathrm{~Hz}, 3 \mathrm{H}) .{ }^{13} \mathrm{C}-\mathrm{NMR}\left(151 \mathrm{MHz}, \mathrm{CDCl}_{3}\right) \delta 134.32,134.22$, 133.20, 129.19, 128.04, 126.35, 125.68, 107.26, 101.58, 97.21, 82.71, 68.42, 48.52, 45.24, 44.09, 39.71, 35.27, $34.56,34.53,32.81,23.87,22.17,19.22,18.78$.

5-(Naphthalen-1-yl)-1-(2-(((3R,6R,8aS,9R,10R,12R,12aR)-3,6,9-trimethyldecahydro-12H-3,12-epoxy[1,2] dioxepino[4,3-i]isochromen-10-yl)oxy)ethyl)-1H-1,2,3-triazole $(\mathbf{8 h}): \quad 5 \quad(60 \mathrm{mg}, \quad 0.183 \mathrm{mmol})$, 1-(naphthalen-1-yl)ethan-1-one $\quad(31.2 \mathrm{mg}, 0.183 \mathrm{mmol}), \quad$ 4-nitrophenyl azide (36.1 $\mathrm{mg}$, $0.220 \mathrm{mmol})$. Reaction time was $36 \mathrm{~h}$. The product was purified by flash column chromatography (first DCM, then EtOAc/heptane $=3: 2)$ to afford $\mathbf{8 h}(49 \mathrm{mg}, 53 \%)$ as an off-white semisolid: ${ }^{1} \mathrm{H}-\mathrm{NMR}$ $\left(400 \mathrm{MHz} \mathrm{CDCl}_{3}\right) \delta 7.97(\mathrm{~d}, J=8.2 \mathrm{~Hz}, 1 \mathrm{H}), 7.92(\mathrm{~d}, J=7.7 \mathrm{~Hz}, 1 \mathrm{H}), 7.79(\mathrm{~s}, 1 \mathrm{H}), 7.58-7.46(\mathrm{~m}, 5 \mathrm{H})$, $5.24(\mathrm{~s}, 1 \mathrm{H}), 4.51(\mathrm{~d}, J=8.0 \mathrm{~Hz}, 1 \mathrm{H}), 4.42-4.34(\mathrm{~m}, 2 \mathrm{H}), 4.13-4.04(\mathrm{~m}, 1 \mathrm{H}), 3.92-3.83(\mathrm{~m}, 1 \mathrm{H}), 1.84-1.78$ $(\mathrm{m}, 1 \mathrm{H}), 1.72-1.58(\mathrm{~m}, 3 \mathrm{H}), 1.57-1.45(\mathrm{~m}, 3 \mathrm{H}), 1.41(\mathrm{~s}, 3 \mathrm{H}), 1.31-1.23(\mathrm{~m}, 1 \mathrm{H}), 1.19-1.09(\mathrm{~m}, 3 \mathrm{H})$, 1.01-0.93 (m, 1H), 0.89-0.80 (m, 6H). ${ }^{13} \mathrm{C}-\mathrm{NMR}\left(101 \mathrm{MHz}, \mathrm{CDCl}_{3}\right) \delta 136.53,134.52,133.76,132.25$, $130.29,129.05,128.66,127.34,126.66,125.27,125.00,124.59,107.13,101.35,97.16,82.65,67.70,48.24$, $45.26,44.05,39.52,35.23,34.56,34.52,32.70,23.83,22.15,19.25,18.76$.

2-Methoxy-4-(1-(2-(((3R,6R,8aS,9R,10R,12R,12aR)-3,6,9-trimethyldecahydro-12H-3,12-epoxy[1,2] dioxepino[4,3-i]isochromen-10-yl)oxy)ethyl)-1H-1,2,3-triazol-5-yl)phenol (8i): 5 (60 mg, $0.183 \mathrm{mmol}$ ), 1-(4-hydroxy-3-methoxyphenyl)ethan-1-one (30.5 mg, $0.183 \mathrm{mmol})$, 4-nitrophenyl azide (36.1 mg, $0.220 \mathrm{mmol}$ ). Reaction time was $36 \mathrm{~h}$. The product was purified by flash column chromatography (first DCM, followed by EtOAc/heptane = 3:2) to give $\mathbf{8 i}$ (35 $\mathrm{mg}, 38 \%$ ) as an off-white semisolid: ${ }^{1} \mathrm{H}-\mathrm{NMR}\left(400 \mathrm{MHz}, \mathrm{CDCl}_{3}\right) \delta 7.64(\mathrm{~s}, 1 \mathrm{H}), 7.01(\mathrm{~s}, 3 \mathrm{H}), 5.86(\mathrm{~s}, 1 \mathrm{H}), 5.34(\mathrm{~s}, 1 \mathrm{H}), 4.59(\mathrm{~d}, J=7.9 \mathrm{~Hz}, 1 \mathrm{H})$, 4.57-4.44 (m, 2H), 4.31-4.21 (m, 1H), 4.11-4.02 (m, 1H), $3.93(\mathrm{~s}, 3 \mathrm{H}), 1.88-1.80(\mathrm{~m}, 1 \mathrm{H}), 1.70-1.58(\mathrm{~m}$, $3 \mathrm{H}), 1.57-1.50(\mathrm{~m}, 3 \mathrm{H}), 1.47(\mathrm{~s}, 3 \mathrm{H}), 1.40-1.31(\mathrm{~m}, 1 \mathrm{H}), 1.30-1.20(\mathrm{~m}, 2 \mathrm{H}), 1.18-1.10(\mathrm{~m}, 1 \mathrm{H}), 1.06-0.96$ $(\mathrm{m}, 1 \mathrm{H}), 0.89-0.81(\mathrm{~m}, 6 \mathrm{H}) .{ }^{13} \mathrm{C}-\mathrm{NMR}\left(101 \mathrm{MHz}, \mathrm{CDCl}_{3}\right) \delta 146.91,138.98,132.62,122.83,118.92,115.07$, $111.85,107.27,101.57,97.25,82.69,68.20,56.29,47.85,45.25,44.10,39.83,35.27,34.56,34.53,32.81,29.84$, $23.84,22.17,19.19,18.77$.

5-Benzyl-1-(2-(((3R,6R,8aS,9R,10R,12R,12aR)-3,6,9-trimethyldecahydro-12H-3,12-epoxy[1,2] dioxepino[4,3-i]isochromen-10-yl)oxy)ethyl)-4,5,6,7-tetrahydro-1H-[1,2,3]triazolo[4,5-c]pyridine (8j): $\mathbf{5}$ (60 mg, $0.183 \mathrm{mmol}), 1$-benzylpiperidin-4-one (34.7 mg, $0.183 \mathrm{mmol})$, 4-nitrophenyl azide (36.1 mg, $0.220 \mathrm{mmol}$ ). Reaction time was $16 \mathrm{~h}$. The product was purified by flash column chromatography (first DCM, next EtOAc/heptane $=3: 2)$ to afford $\mathbf{8 j}(61 \mathrm{mg}, 63 \%)$ as an off-white semisolid: ${ }^{1} \mathrm{H}-\mathrm{NMR}(400$ $\left.\mathrm{MHz} \mathrm{CDCl}_{3}\right) \delta 7.38-7.28(\mathrm{~m}, 5 \mathrm{H}), 5.37(\mathrm{~s}, 1 \mathrm{H}), 4.60(\mathrm{~d}, J=7.9 \mathrm{~Hz}, 1 \mathrm{H}), 4.52-4,46(\mathrm{~m}, 1 \mathrm{H}), 4.42-4.34$ $(\mathrm{m}, 1 \mathrm{H}), 4.23-4.17(\mathrm{~m}, 1 \mathrm{H}), 3.90-3.82(\mathrm{~m}, 1 \mathrm{H}), 3.75(\mathrm{~s}, 2 \mathrm{H}), 3.72-3.64(\mathrm{~m}, 2 \mathrm{H}), 2.85-2.68(\mathrm{~m}, 4 \mathrm{H})$, $1.85-1.81(\mathrm{~m}, 1 \mathrm{H}), 1.70-1.53(\mathrm{~m}, 6 \mathrm{H}), 1.47(\mathrm{~s}, 3 \mathrm{H}), 1.39-1.36(\mathrm{~m}, 1 \mathrm{H}), 1.34-1.26(\mathrm{~m}, 1 \mathrm{H}), 1.95-1.12$ 
(m, 2H), 1.08-0.99 (m, 1H), 0.92-0.83 (m, 6H). ${ }^{13} \mathrm{C}-\mathrm{NMR}\left(101 \mathrm{MHz}, \mathrm{CDCl}_{3}\right) \delta 142.03,138.18,131.76$, $129.08,128.52$, 127.46, 107.26, 101.43, 97.23, 82.71, 68.54, 61.64, 49.92, 49.39, 48.23, 45.25, 44.14, 39.93, $35.26,34.55,34.52,32.81,29.82,23.86,22.16,20.99,19.28,18.76$.

(1S,3aS,3bR,5aS,10aS,10bS,12aS)-10a,12a-Dimethyl-7-(2-(((3R,6R,8aS,9R,10R,12R,12aR)-3,6,9-trimethyldecahydro-12H-3,12-epoxy[1,2]dioxepino[4,3-i]isochromen-10-yl)oxy)ethyl)-1,2,3,3a,3b,4,5,5a,6,7,10,10a, 10b,11,12,12a-hexadecahydrocyclopenta[7,8]phenanthro[2,3-d][1,2,3]triazol-1-ol (8k): 5 (60 mg, $0.183 \mathbf{m m o l}$ ), (5S,8R,9S,10S,13S,14S,17S)-17-hydroxy-10,13-dimethylhexadecahydro-3H-cyclopenta[a]phenanthren3-one ( $53.2 \mathrm{mg}, 0.183 \mathrm{mmol})$, 4-nitrophenyl azide $(36.1 \mathrm{mg}, 0.220 \mathrm{mmol})$. Reaction time was $16 \mathrm{~h}$. Flash column chromatography (first DCM, followed by EtOAc/heptane $=3: 2$ ) yielded $8 \mathbf{k}(72 \mathrm{mg}, 63 \%$ ) as an off-white solid: m.p. $96-97{ }^{\circ} \mathrm{C} ;{ }^{1} \mathrm{H}-\mathrm{NMR}\left(400 \mathrm{MHz}, \mathrm{CDCl}_{3}\right) \delta 5.39(\mathrm{~s}, 1 \mathrm{H}), 4.61(\mathrm{~d}, J=7.9 \mathrm{~Hz}, 1 \mathrm{H})$, $4.48(\mathrm{dt}, J=14.2,4.2 \mathrm{~Hz}, 1 \mathrm{H}), 4.40-4.31(\mathrm{~m}, 1 \mathrm{H}), 4.20(\mathrm{dt}, J=8.9,4.4 \mathrm{~Hz}, 1 \mathrm{H}), 3.91-3.85(\mathrm{~m}, 1 \mathrm{H}), 3.66$ $(\mathrm{t}, J=8.5 \mathrm{~Hz}, 1 \mathrm{H}), 2.85(\mathrm{~d}, J=15.3 \mathrm{~Hz}, 1 \mathrm{H}), 2.55(\mathrm{dd}, J=16.2,5.0 \mathrm{~Hz}, 1 \mathrm{H}), 2.30(\mathrm{t}, J=13.6 \mathrm{~Hz}, 2 \mathrm{H})$, 2.11-2.03 (m, 1H), $1.89-1.82(\mathrm{~m}, 2 \mathrm{H}), 1.75-1.51(\mathrm{~m}, 10 \mathrm{H}), 1.48-1.47(\mathrm{~m}, 3 \mathrm{H}), 1.45-1.38(\mathrm{~m}, 3 \mathrm{H}), 1.32-1.25$ $(\mathrm{m}, 3 \mathrm{H}), 1.20-1.12(\mathrm{~m}, 3 \mathrm{H}), 1.05-0.96(\mathrm{~m}, 2 \mathrm{H}), 0.91-0.87(\mathrm{~m}, 6 \mathrm{H}), 0.76(\mathrm{~s}, 3 \mathrm{H}), 0.72(\mathrm{~s}, 3 \mathrm{H}) .{ }^{13} \mathrm{C}-\mathrm{NMR}$ $\left(151 \mathrm{MHz}, \mathrm{CDCl}_{3}\right) \delta 142.96,131.85,107.28,101.25,97.27,82.74,81.99,68.40,53.86,50.95,48.03,45.26$, $44.14,43.00,42.39,39.98,36.96,36.78,36.31,35.75,35.32,34.56,34.54,32.84,31.34,30.60,29.05,25.01$, $23.87,23.58,22.18,20.93,19.39,18.78,11.73,11.17$.

$(1 R, 3 a S, 5 a R, 5 b R, 7 a R, 12 a R, 12 b R, 14 a R, 14 b R)-5 a, 5 b, 8,8,12 a-P e n t a m e t h y l-1$-(prop-1-en-2-yl)-9-(2-(( $(3 R, 6 R, 8 a S$, 9R,10R,12R,12aR)-3,6,9-trimethyldecahydro-12H-3,12-epoxy[1,2]dioxepino[4,3-i]isochromen-10-yl)-oxy)ethyl)$2,3,4,5,5 a, 5 b, 6,7,7 a, 8,9,12,12 a, 12 b, 13,14,14 a, 14 b$-octadecahydrocyclopenta[7,8]chryseno[2,3-d][1,2,3]triazole$3 a(1 H)$-carboxylic acid (81): $5(60 \mathrm{mg}, 0.183 \mathrm{mmol}),(1 R, 3 \mathrm{a} S, 5 \mathrm{a} R, 5 \mathrm{~b} R, 7 \mathrm{a} R, 11 \mathrm{a} R, 11 \mathrm{~b} R, 13 \mathrm{a} R, 13 \mathrm{~b} R)-$ $5 \mathrm{a}, 5 \mathrm{~b}, 8,8,11 \mathrm{a}-$ pentamethyl-9-oxo-1-(prop-1-en-2-yl)icosahydro-3aH-cyclopenta[ $a]$ chrysene-3a-carboxylic acid ( $83 \mathrm{mg}, 0.183 \mathrm{mmol})$, 4-nitrophenyl azide $(36.1 \mathrm{mg}, 0.220 \mathrm{mmol})$. Reaction time was $16 \mathrm{~h}$. The product was purified by flash column chromatography (first DCM, followed by EtOAc/heptane $=3: 2$ ) to afford $81(68 \mathrm{mg}, 47 \%)$ as an off-white semisolid: ${ }^{1} \mathrm{H}-\mathrm{NMR}\left(400 \mathrm{MHz}, \mathrm{CDCl}_{3}\right) \delta 5.39(\mathrm{~s}, 1 \mathrm{H}), 4.76$ $(\mathrm{s}, 1 \mathrm{H}), 4.69-4.63(\mathrm{~m}, 2 \mathrm{H}), 4.59-4.51(\mathrm{~m}, 1 \mathrm{H}), 4.28-4.23(\mathrm{~m}, 1 \mathrm{H}), 4.19-4.11(\mathrm{~m}, 1 \mathrm{H}), 3.06-3.00(\mathrm{~m}, 1 \mathrm{H})$, $2.91(\mathrm{~d}, J=15.3 \mathrm{~Hz}, 1 \mathrm{H}), 2.31-2.23(\mathrm{~m}, 2 \mathrm{H}), 2.12(\mathrm{~d}, J=15.3 \mathrm{~Hz}, 1 \mathrm{H}), 2.03-1.96(\mathrm{~m}, 2 \mathrm{H}), 1.86-1.76$ $(\mathrm{m}, 3 \mathrm{H}), 1.71(\mathrm{~s}, 3 \mathrm{H}), 1.69-1.63(\mathrm{~m}, 3 \mathrm{H}), 1.60-1.50(\mathrm{~m}, 8 \mathrm{H}), 1.48(\mathrm{~s}, 5 \mathrm{H}), 1.45-1.39(\mathrm{~m}, 2 \mathrm{H}), 1.37$ $(\mathrm{d}, J=2.5 \mathrm{~Hz}, 1 \mathrm{H}), 1.32(\mathrm{~d}, J=7.6 \mathrm{~Hz}, 4 \mathrm{H}), 1.29-1.22(\mathrm{~m}, 9 \mathrm{H}), 1.18-1.10(\mathrm{~m}, 3 \mathrm{H}), 1.00(\mathrm{~d}, J=4.6 \mathrm{~Hz}, 6 \mathrm{H})$, $0.90-0.87(\mathrm{~m}, 6 \mathrm{H}), 0.78(\mathrm{~s}, 3 \mathrm{H}) .{ }^{13} \mathrm{C}-\mathrm{NMR}\left(101 \mathrm{MHz}, \mathrm{CDCl}_{3}\right) \delta 180.60,150.37,141.10,138.35,110.01$, 107.26, 101.71, 97.31, 82.75, 68.55, 56.48, 54.86, 49.47, 49.31, 49.21, 47.00, 45.30, 44.10, 42.61, 40.75, 39.80, $39.09,38.59,38.42,37.18,35.29,34.60,34.56,33.76,33.54,32.82,32.22,30.71,29.94,29.84,28.82,25.65$, $23.90,22.19,21.57,19.55,19.33,19.09,18.80,16.17,15.80,14.83$.

(3R,6R,8aS,9R,12R,12aR)-3,6,9-Trimethyldecahydro-12H-3,12-epoxy[1,2]dioxepino[4,3-i]isochromen-10-yl 4-oxocyclohexane-1-carboxylate (9): dihydroartemisinin (1 gm, $3.52 \mathrm{mmol})$, dicyclohexyl-methanediimine (0.726 gm, $3.52 \mathrm{mmol})$, 4-oxocyclohexane-1-carboxylic acid (0.600 gm, $4.22 \mathrm{mmol})$, $\mathrm{N}, \mathrm{N}$-dimethylpyridin-4-amine (0.064 gm,0.528 mmol.). Reaction time was $18 \mathrm{~h}$. The product was purified by flash column chromatography $(\mathrm{DCM} / \mathrm{MeOH}=99 / 1)$ to give $9(1.2 \mathrm{gm}, 84 \%)$ as an off-white semisolid: ${ }^{1} \mathrm{H}-\mathrm{NMR}\left(400 \mathrm{MHz}, \mathrm{CDCl}_{3}\right) \delta 5.82(\mathrm{~d}, J=9.8 \mathrm{~Hz}, 1 \mathrm{H}), 5.45(\mathrm{~s}, 1 \mathrm{H}), 2.91-2.75$ $(\mathrm{m}, 1 \mathrm{H}), 2.60(\mathrm{ddd}, J=9.9,7.2,4.6 \mathrm{~Hz}, 1 \mathrm{H}), 2.62-2.58(\mathrm{~m}, 1 \mathrm{H}), 2.55-2.45(\mathrm{~m}, 1 \mathrm{H}), 2.39-2.34(\mathrm{~m}, 2 \mathrm{H})$, 2.33-2.27 (m, 1H), 2.25-2.20 (m, 1H), 2.14-2.00 (m, 3H), 1.95-1.87 (m, 1H), 1.81-1.75 (m, 2H), 1.67-1.56 $(\mathrm{m}, 2 \mathrm{H}), 1.52-1.46(\mathrm{~m}, 1 \mathrm{H}), 1.45-1.41(\mathrm{~m}, 3 \mathrm{H}), 1.39-1.25(\mathrm{~m}, 3 \mathrm{H}), 1.11-1.00(\mathrm{~m}, 1 \mathrm{H}), 0.97(\mathrm{~d}, J=6.0 \mathrm{~Hz}$, $3 \mathrm{H}), 0.86(\mathrm{~d}, J=7.1 \mathrm{~Hz}, 3 \mathrm{H}) .{ }^{13} \mathrm{C}-\mathrm{NMR}\left(101 \mathrm{MHz}, \mathrm{CDCl}_{3}\right) \delta 210.13,173.04,104.63,92.27,91.67,80.25$, $77.48,76.84,51.70,45.39,40.70,39.87,39.66,37.41,36.33,34.21,31.94,28.78,28.05,26.06,24.71,22.13$, $20.34,12.30$.

(3R,6R,8aS,9R,10S,12R,12aR)-3,6,9-Trimethyldecahydro-12H-3,12-epoxy[1,2]dioxepino[4,3-i]isochromen-10-yl 1-(4-methylbenzyl)-4,5,6,7-tetrahydro-1H-benzo[d][1,2,3]triazole-5-carboxylate (11a): 9 (60 mg, $0.147 \mathrm{mmol}$ ), p-tolylmethanamine (18 mg, $0.147 \mathrm{mmol})$, 4-nitrophenyl azide ( $28.9 \mathrm{mg}, 0.176 \mathrm{mmol})$. Reaction time 
was $16 \mathrm{~h}$. Flash column chromatography (first DCM, followed by EtOAc/heptane = 3:2) afforded purified 11a (53 mg, 67\%) as an off-white semisolid: ${ }^{1} \mathrm{H}-\mathrm{NMR}\left(400 \mathrm{MHz}, \mathrm{CDCl}_{3}\right) \delta 7.14(\mathrm{~d}, J=7.8 \mathrm{~Hz}$, $2 \mathrm{H}), 7.08(\mathrm{~d}, J=7.8 \mathrm{~Hz}, 2 \mathrm{H}), 5.83-5.69(\mathrm{~m}, 1 \mathrm{H}), 5.48-5.29(\mathrm{~m}, 3 \mathrm{H}), 3.20-3.05(\mathrm{~m}, 1 \mathrm{H}), 3.03-2.91(\mathrm{~m}, 1 \mathrm{H})$, 2.86-2.76 (m, 1H), 2.68-2.50 (m, 2H), 2.44-2.36 (m, H), $2.33(\mathrm{~s}, 3 \mathrm{H}), 2.29-2.12(\mathrm{~m}, 1 \mathrm{H}), 2.07-1.99(\mathrm{~m}$, $1 \mathrm{H}), 1.95-1.85(\mathrm{~m}, 2 \mathrm{H}), 1.79-1.69(\mathrm{~m}, 2 \mathrm{H}), 1.66-1.57(\mathrm{~m}, 2 \mathrm{H}), 1.54-1.45(\mathrm{~m}, 1 \mathrm{H}), 1.42(\mathrm{~d}, J=1.6 \mathrm{~Hz}, 3 \mathrm{H})$, $1.38-1.25(\mathrm{~m}, 3 \mathrm{H}), 0.96(\mathrm{~d}, J=5.8 \mathrm{~Hz}, 3 \mathrm{H}), 0.80(\mathrm{~d}, J=7.1 \mathrm{~Hz}, 3 \mathrm{H}) .{ }^{13} \mathrm{C}-\mathrm{NMR}\left(151 \mathrm{MHz}, \mathrm{CDCl}_{3}\right) \delta 173.24$, 172.94, 141.10, 141.06, 136.27, 136.21, 132.13, 127.09, 127.02, 122.90, 122.73, 122.40, 122.24, 119.72, 119.63, $118.14,118.05,111.69,111.62,111.23,104.76,104.72,92.59,92.53,91.82,80.38,80.22,51.74,51.70,48.99$, $48.80,45.35,39.53,39.38,37.40,36.38,34.18,32.02,31.90,26.77,26.68,26.03,25.92,25.02,24.80,24.69$, $24.35,23.84,22.15,20.34,18.23,18.04,12.32,12.22$.

(3R,6R,8aS,9R,10S,12R,12aR)-3,6,9-Trimethyldecahydro-12H-3,12-epoxy[1,2]dioxepino[4,3-i]isochromen-10-yl 1-(3,4,5-trimethoxybenzyl)-4,5,6,7-tetrahydro-1H-benzo[d][1,2,3]triazole-5-carboxylate (11b): 9 (60 mg, $0.147 \mathrm{mmol}),(3,4,5$-trimethoxyphenyl)methanamine $(29 \mathrm{mg}, 0.147 \mathrm{mmol}), 4$-nitrophenyl azide ( $28.9 \mathrm{mg}, 0.176 \mathrm{mmol})$. Reaction time was $16 \mathrm{~h}$. The product was purified by flash column chromatography (DCM at first, followed by EtOAc/heptane $=3: 2)$ to afford $\mathbf{1 1 b}(55 \mathrm{mg}, 61 \%)$ as an off-white solid: $\mathrm{mp} 80-81^{\circ} \mathrm{C} ;{ }^{1} \mathrm{H}-\mathrm{NMR}\left(400 \mathrm{MHz}, \mathrm{CDCl}_{3}\right) \delta 6.40(\mathrm{~d}, J=6.8 \mathrm{~Hz}, 2 \mathrm{H}), 5.82-5.74(\mathrm{~m}, 1 \mathrm{H})$, $5.43(\mathrm{t}, J=4.6 \mathrm{~Hz}, 1 \mathrm{H}), 5.39-5.28(\mathrm{~m}, 2 \mathrm{H}), 3.83(\mathrm{~d}, J=1.0 \mathrm{~Hz}, 3 \mathrm{H}), 3.81(\mathrm{~d}, J=1.5 \mathrm{~Hz}, 6 \mathrm{H}), 3.20-2.94$ (m, 2H), 2.88-2.81 (m, 1H), 2.74-2.54 (m, 2H), 2.52-2.42 (m, 1H), 2.42-2.33 (m, 1H), 2.31-2.20 (m, 1H), $2.02-1.86(\mathrm{~m}, 2 \mathrm{H}), 1.79-1.68(\mathrm{~m}, 2 \mathrm{H}), 1.66-1.59(\mathrm{~m}, 1 \mathrm{H}), 1.42(\mathrm{~d}, J=3.5 \mathrm{~Hz}, 3 \mathrm{H}), 1.32-1.23(\mathrm{~m}, 4 \mathrm{H}), 0.97$ $(\mathrm{d}, J=5.8 \mathrm{~Hz}, 3 \mathrm{H}), 0.90-0.84(\mathrm{~m}, 2 \mathrm{H}), 0.81(\mathrm{~d}, J=7.1 \mathrm{~Hz}, 3 \mathrm{H}) .{ }^{13} \mathrm{C}-\mathrm{NMR}\left(101 \mathrm{MHz}, \mathrm{CDCl}_{3}\right) \delta 173.06$, $172.85,153.77,142.64,142.33,138.12,131.47,131.12,130.33,130.30,104.73,104.66,104.61,104.57,92.30$, $91.65,80.22,80.20,60.97,56.34,52.31,52.28,51.67,45.37,45.33,39.82,39.47,37.39,36.31,34.18,31.92$, $31.87,29.81,26.03,25.47,24.99,24.68,24.20,22.09,20.31,19.29,18.87,12.24,12.16$.

(3R,6R,8aS,9R,10S,12R,12aR)-3,6,9-Trimethyldecahydro-12H-3,12-epoxy[1,2]dioxepino[4,3-i]isochromen-10-yl 1-(benzo[d][1,3]dioxol-5-ylmethyl)-4,5,6,7-tetrahydro-1H-benzo[d][1,2,3]triazole-5-carboxylate (11c): 9 (60 mg, $0.147 \mathrm{mmol})$, benzo[d][1,3]dioxol-5-ylmethanamine (22.2 mg, $0.147 \mathrm{mmol})$, 4-nitrophenyl azide ( $28.9 \mathrm{mg}, 0.176 \mathrm{mmol}$ ). Reaction time was $16 \mathrm{~h}$. The product was purified by flash column chromatography (first DCM, followed by EtOAc/heptane $=3: 2)$ to give $11 \mathrm{c}(51 \mathrm{mg}, 61 \%)$ as an off-white semisolid: ${ }^{1} \mathrm{H}-\mathrm{NMR}\left(400 \mathrm{MHz}, \mathrm{CDCl}_{3}\right) \delta 6.76(\mathrm{dd}, J=6.9,1.7 \mathrm{~Hz}, 1 \mathrm{H}), 6.68(\mathrm{dt}, J=3.7$, $1.6 \mathrm{~Hz}, 2 \mathrm{H}), 5.96(\mathrm{~s}, 2 \mathrm{H}), 5.83-5.73(\mathrm{~m}, 1 \mathrm{H}), 5.43(\mathrm{~d}, J=3.0 \mathrm{~Hz}, 1 \mathrm{H}), 5.39-5.25(\mathrm{~m}, 2 \mathrm{H}), 3.18-3.06(\mathrm{~m}, 1 \mathrm{H})$, 3.04-2.92 (m, 1H), 2.87-2.78 (m, 1H), 2.69-2.54 (m, 2H), 2.47-2.33 (m, 2H), 2.28-2.19 (m, 1H), 2.06-1.86 $(\mathrm{m}, 3 \mathrm{H}), 1.79-1.69(\mathrm{~m}, 2 \mathrm{H}), 1.66-1.58(\mathrm{~m}, 1 \mathrm{H}), 1.51-1.45(\mathrm{~m}, 1 \mathrm{H}), 1.42(\mathrm{~d}, J=1.9 \mathrm{~Hz}, 3 \mathrm{H}), 1.34-1.24$ $(\mathrm{m}, 2 \mathrm{H}), 1.07-0.98(\mathrm{~m}, 1 \mathrm{H}), 0.96(\mathrm{~d}, J=5.9 \mathrm{~Hz}, 3 \mathrm{H}), 0.91-0.84(\mathrm{~m}, 1 \mathrm{H}), 0.83-0.78(\mathrm{~m}, 3 \mathrm{H}) .{ }^{13} \mathrm{C}-\mathrm{NMR}$ $\left(101 \mathrm{MHz}, \mathrm{CDCl}_{3}\right) \delta 173.09,172.92,148.40,147.87,142.33,131.34,128.43,121.33,108.54,108.21,108.19$, $104.59,104.55,101.45,92.29,91.64,80.22,80.19,51.98,51.67,45.38,45.33,39.47,37.38,37.36,36.31,34.18$, $31.92,31.86,26.04,25.50,24.99,24.67,24.23,22.08,20.31,19.36,18.86,12.15$.

(3R,6R,8aS,9R,10S,12R,12aR)-3,6,9-Trimethyldecahydro-12H-3,12-epoxy[1,2]dioxepino[4,3-i]isochromen-10-yl 1-(2-(1H-indol-3-yl)ethyl)-4,5,6,7-tetrahydro-1H-benzo[d][1,2,3]triazole-5-carboxylate (11d): 9 (60 mg, $0.147 \mathrm{mmol}), 2-(1 \mathrm{H}$-indol-3-yl)ethan-1-amine $(25.5 \mathrm{mg}, 0.147 \mathrm{mmol}), 4$-nitrophenyl azide $(28.9 \mathrm{mg}$, $0.176 \mathrm{mmol})$. Reaction time was $16 \mathrm{~h}$. The product was purified by flash column chromatography (first DCM, followed by EtOAc/heptane $=3: 2$ ) to afford 11d $(39 \mathrm{mg}, 46 \%)$ as an off-white semisolid: ${ }^{1} \mathrm{H}-\mathrm{NMR}\left(400 \mathrm{MHz}, \mathrm{CDCl}_{3}\right) \delta 8.42(\mathrm{~d}, J=7.1 \mathrm{~Hz}, 1 \mathrm{H}), 7.43-7.33(\mathrm{~m}, 2 \mathrm{H}), 7.22-7.16(\mathrm{~m}, 1 \mathrm{H}), 7.11-7.06$ $(\mathrm{m}, 1 \mathrm{H}), 6.70(\mathrm{dd}, J=51.1,2.3 \mathrm{~Hz}, 1 \mathrm{H}), 5.73(\mathrm{dd}, J=9.9,6.4 \mathrm{~Hz}, 1 \mathrm{H}), 5.47(\mathrm{~d}, J=13.4 \mathrm{~Hz}, 1 \mathrm{H}), 4.53-4.31$ $(\mathrm{m}, 2 \mathrm{H}), 3.37-3.24(\mathrm{~m}, 2 \mathrm{H}), 3.06-2.87(\mathrm{~m}, 2 \mathrm{H}), 2.70-2.55(\mathrm{~m}, 2 \mathrm{H}), 2.42-2.32(\mathrm{~m}, 1 \mathrm{H}), 2.03(\mathrm{ddd}, J=14.5$, 7.3, $4.2 \mathrm{~Hz}, 1 \mathrm{H}), 1.93-1.85(\mathrm{~m}, 3 \mathrm{H}), 1.82-1.74(\mathrm{~m}, 2 \mathrm{H}), 1.72-1.61(\mathrm{~m}, 4 \mathrm{H}), 1.54-1.41(\mathrm{~m}, 1 \mathrm{H}), 1.41-1.34(\mathrm{~m}$, $4 \mathrm{H}), 1.34-1.25(\mathrm{~m}, 2 \mathrm{H}), 0.97(\mathrm{~d}, J=5.6 \mathrm{~Hz}, 3 \mathrm{H}), 0.83(\mathrm{~d}, J=7.1 \mathrm{~Hz}, 3 \mathrm{H}) .{ }^{13} \mathrm{C}-\mathrm{NMR}\left(151 \mathrm{MHz}, \mathrm{CDCl}_{3}\right) \delta$ 173.24, 172.94, 141.10, 141.06, 136.27, 136.21, 132.13, 127.09, 127.02, 122.90, 122.73, 122.40, 122.24, 119.72, $119.63,118.14,118.05,111.69,111.62,111.23,104.76,104.72,92.59,92.53,91.82,80.38,80.22,51.74,51.70$, 


\section{Conclusions}

In conclusion, a series of newly functionalized artemisinin derivatives has been prepared by using a organocatalytic multicomponent reaction. The starting precursors 5 and $\mathbf{9}$ were used for triazolization reactions resulting in the formation of fused and 1,5-disubstituted 1,2,3-triazole derivatives. All derivatives were screened against HIV wt and three of the molecules exhibited moderate activity. The $\beta$-tetralone derivatives $\mathbf{8 b}, \mathbf{8} \mathbf{c}$, and $\mathbf{8 e}$ were inhibitory to HIV-1 replication in cell culture with a limited cytotoxicity. However, no inhibitory activity was observed against HIV-2 and an NNRTI-resistant double RT mutant (K103N; Y181C) HIV-1 strain (RES056), pointing at an NNRTI-type mode of action for the active derivatives. Further studies on modification of artemisinin by triazolization reactions are under investigation and will be reported in due time.

Supplementary Materials: Supplementary materials are available online.

Acknowledgments: We thank Katholieke Universiteit Leuven for financial support. Erasmus Mundus Lot 13, Euro-India is acknowledged for the doctoral fellowship to Sampad Jana and also we thank Higher Education Commission of Pakistan for providing funding to Shabina Iram (No. 1-8/HEC/HRD/2015/3687) under the International Research Support Initiative Program (IRSIP). We thank K. Erven, K. Uyttersprot and C. Heens for technical assistance with the HIV assays.

Author Contributions: W.D., S.J., and J.T. designed the research. S.J., S.I., C.P., and M.Q.H performed the experiments. W.D., C.P., and S.J. analyzed the data. S.J. and S.I. wrote the paper.

Conflicts of Interest: The authors declare no conflict of interest.

\section{References}

1. Gallo, R.C.; Sarin, P.S.; Gelmann, E.P.; Robert-Guroff, M.; Richardson, E.; Kalyanaraman, V.S.; Mann, D.; Sidhu, G.D.; Stahl, R.E.; Zolla-Pazner, S.; et al. Isolation of human T-cell leukemia virus in acquired immune deficiency syndrome (AIDS). Science 1983, 220, 865-867. [CrossRef] [PubMed]

2. Zhao, Y.; Gu, Q.; Morris-Natschke, S.L.; Chen, C.H.; Lee, K.H. Incorporation of Privileged Structures into Bevirimat Can Improve Activity against Wild-Type and Bevirimat-Resistant HIV-1. J. Med. Chem. 2016, 59, 9262-9268. [CrossRef] [PubMed]

3. Zhan, P.; Pannecouque, C.; De Clercq, E.; Liu, X. Anti-HIV drug discovery and development: Current innovations and future trends. J. Med. Chem. 2015, 59, 2849-2878. [CrossRef] [PubMed]

4. Tu, Y. The discovery of artemisinin (qinghaosu) and gifts from Chinese medicine. Nat. Med. 2011, 17, 1217-1220. [CrossRef] [PubMed]

5. Chaturvedi, D.; Goswami, A.; Saikia, P.P.; Barua, N.C.; Rao, P.G. Artemisinin and its derivatives: A novel class of anti-malarial and anti-cancer agents. Chem. Soc. Rev. 2010, 39, 435-454. [CrossRef] [PubMed]

6. Klayman, D.L. Qinghaosu (artemisinin): An antimalarial drug from China. Science 1985, 228, $1049-1055$. [CrossRef] [PubMed]

7. Jung, M.; Lee, K.; Kim, H.; Park, M. Recent advances in artemisinin and its derivatives as antimalarial and antitumor agents. Curr. Med. Chem. 2004, 11, 1265-1284. [CrossRef] [PubMed]

8. Li, Y.; Wu, J.M.; Shan, F.; Wu, G.S.; Ding, J.; Xiao, D.; Han, J.X.; Atassi, G.; Leonce, S.; Caignard, D.H.; et al. Synthesis and cytotoxicity of dihydroartemisinin ethers containing cyanoarylmethyl group. Bioorg. Med. Chem. 2003, 11, 977-984. [CrossRef]

9. Qi, L.; Yang, Y.; Liu, Y.C.; Zhu, T.X.; Jin, S.; Zang, L.; Zhang, Y.Y.; Ren, K. The inhibitory effect of dihydroartemisinin on the growth of neuroblastoma cells. Asian Pac. J. Trop. Biomed. 2016, 6, $279-282$. [CrossRef]

10. Lu, J.J.; Chen, S.M.; Zhang, X.W.; Ding, J.; Meng, L.H. The anti-cancer activity of dihydroartemisinin is associated with induction of iron-dependent endoplasmic reticulum stress in colorectal carcinoma HCT116 cells. Investig. New Drugs 2011, 29, 1276-1283. [CrossRef] [PubMed]

11. Zhou, H.J.; Wang, Z.; Li, A. Dihydroartemisinin induces apoptosis in human leukemia cells HL60 via downregulation of transferrin receptor expression. Anticancer Drugs 2008, 19, 247-255. [CrossRef] [PubMed] 
12. Mu, D.; Zhang, W.; Chu, D.; Liu, T.; Xie, Y.; Fu, E.; Jin, F. The role of calcium, P38 MAPK in dihydroartemisinin-induced apoptosis of lung cancer PC-14 cells. Cancer Chemother. Pharmacol. 2008, 61, 639-645. [CrossRef] [PubMed]

13. Disbrow, G.L.; Baege, A.C.; Kierpiec, K.A.; Yuan, H.; Centeno, J.A.; Thibodeaux, C.A.; Hartmann, D.; Schlegel, R. Dihydroartemisinin is cytotoxic to papillomavirus-expressing epithelial cells in vitro and in vivo. Cancer Res. 2005, 65, 10854-10861. [CrossRef] [PubMed]

14. Chen, H.; Sun, B.; Pan, S.; Jiang, H.; Sun, X. Dihydroartemisinin inhibits growth of pancreatic cancer cells in vitro and in vivo. Anticancer Drugs 2009, 20, 131-140. [CrossRef] [PubMed]

15. Chen, T.; Li, M.; Zhang, R.; Wang, H. Dihydroartemisinin induces apoptosis and sensitizes human ovarian cancer cells to carboplatin therapy. J. Cell. Mol. Med. 2009, 13, 1358-1370. [CrossRef] [PubMed]

16. Lu, Y.Y.; Chen, T.S.; Qu, J.L.; Pan, W.L.; Sun, L.; Wei, X.B. Dihydroartemisinin (DHA) induces caspase-3-dependent apoptosis in human lung adenocarcinoma ASTC-a-1 cells. J. Biomed. Sci. 2009, 16, 16. [CrossRef] [PubMed]

17. Lu, J.J.; Meng, L.H.; Cai, Y.J.; Chen, Q.; Tong, L.J.; Lin, L.P.; Ding, J. Dihydroartemisinin induces apoptosis in HL-60 leukemia cells dependent of iron and p38 mitogen-activated protein kinase activation but independent of reactive oxygen species. Cancer Biol. Ther. 2008, 7, 1017-1023. [CrossRef] [PubMed]

18. Feng, T.S.; Guantai, E.M.; Nell, M.J.; van Rensburg, C.E.; Hoppe, H.C.; Chibale, K. Antiplasmodial and antitumor activity of dihydroartemisinin analogs derived via the aza-Michael addition reaction. Bioorg. Med. Chem. Lett. 2011, 21, 2882-2886. [CrossRef] [PubMed]

19. Wu, C.; Liu, J.; Pan, X.; Xian, W.; Li, B.; Peng, W.; Wang, J.; Yang, D.; Zhou, H. Design, synthesis and evaluation of the antibacterial enhancement activities of amino dihydroartemisinin derivatives. Molecules 2013, 18, 6866-6882. [CrossRef] [PubMed]

20. Flobinus, A.; Taudon, N.; Desbordes, M.; Labrosse, B.; Simon, F.; Mazeron, M.C.; Schnepf, N. Stability and antiviral activity against human cytomegalovirus of artemisinin derivatives. J. Antimicrob. Chemother. 2014, 69, 34-40. [CrossRef] [PubMed]

21. Yang, Z.S.; Zhou, W.L.; Sui, Y.; Wang, J.X.; Wu, J.M.; Zhou, Y.; Zhang, Y.; He, P.L.; Han, J.Y.; Tang, W.; et al. Synthesis and immunosuppressive activity of new artemisinin derivatives. 1. [12( $\beta$ or $\alpha$ )-dihydroartemisininoxy]phen(ox)yl aliphatic acids and esters. J. Med. Chem. 2005, 48, 4608-4617. [PubMed]

22. Nontprasert, A.; Pukrittayakamee, S.; Prakongpan, S.; Supanaranond, W.; Looareesuwan, S.; White, N.J. Assessment of the neurotoxicity of oral dihydroartemisinin in mice. Trans. R. Soc. Trop. Med. Hyg. 2002, 96, 99-101. [CrossRef]

23. Cloete, T.T.; Krebs, H.J.; Clark, J.A.; Connelly, M.C.; Orcutt, A.; Sigal, M.S.; Guy, R.K.; N’Da, D.D. Antimalarial activity of 10-alkyl/aryl esters and amino ethylethers of artemisinin. Bioorg. Chem. 2013, 46, 10-16. [CrossRef] [PubMed]

24. Ashley, E.A.; Dhorda, M.; Fairhurst, R.M.; Amaratunga, C.; Lim, P.; Suon, S.; Sreng, S.; Anderson, J.M.; Mao, S.; Sam, B.; et al. Spread of artemisinin resistance in Plasmodium falciparum malaria. N. Eng. J. Med. 2014, 371, 411-423. [CrossRef] [PubMed]

25. Saikia, B.; Saikia, P.P.; Goswami, A.; Barua, N.C.; Saxena, A.K.; Suri, N. Synthesis of a novel series of 1,2,3-triazole-containing artemisinin dimers with potent anticancer activity involving Huisgen 1,3-dipolar cycloaddition reaction. Synthesis 2011, 19, 3173-3179.

26. Binh, L.H.; Van, N.T.T.; Kien, V.T.; Van Chinh, L.; Nga, N.T.; Tien, H.X.; Vu, T.K. Synthesis and in vitro cytotoxic evaluation of new triazole derivatives based on artemisinin via click chemistry. Med. Chem. Res. 2016, 25, 738-750. [CrossRef]

27. Thomas, J.; Jana, S.; John, J.; Liekens, S.; Dehaen, W. A General Metal-Free Route Towards the Synthesis of 1,2,3-Triazoles from Readily Available Primary Amines and Ketones. Chem. Commun. 2016, 52, 2885-2888. [CrossRef] [PubMed]

28. Thomas, J.; Jana, S.; Liekens, S.; Dehaen, W. A single-step acid catalyzed reaction for rapid assembly of NH-1,2,3-triazoles. Chem. Commun. 2016, 52, 9236-9239. [CrossRef] [PubMed]

29. Jana, S.; Thomas, J.; Dehaen, W. A One-Pot Procedure for the Synthesis of "Click-Ready" Triazoles from Ketones. J. Org. Chem. 2016, 81, 12426-12432. [CrossRef] [PubMed] 
30. Liu, Y.; Liu, Z.; Shi, J.; Chen, H.; Mi, B.; Li, P.; Gong, P. Synthesis and Cytotoxicity of Novel 10-Substituted Dihydroartemisinin Derivatives Containing N-Arylphenyl-ethenesulfonamide Groups. Molecules 2013, 18, 2864-2877. [CrossRef] [PubMed]

31. Pannecouque, C.; Daelemans, D.; De Clercq, E. Tetrazolium-based colorimetric assay for the detection of HIV replication inhibitors: revisited 20 years later. Nat. Protoc. 2008, 3, 427-434. [CrossRef] [PubMed]

Sample Availability: Samples of the synthesized compounds are available from the authors.

(C) 2017 by the authors; licensee MDPI, Basel, Switzerland. This article is an open access article distributed under the terms and conditions of the Creative Commons Attribution (CC BY) license (http:/ / creativecommons.org/licenses/by/4.0/). 